(A) Check for updates

Cite this: Food Funct., 2018, 9, 3698

\title{
Nanodispersions of beta-carotene: effects on antioxidant enzymes and cytotoxic properties
}

\author{
Felipe Rocha, ${ }^{a}$ Letícia Yumi Sugahara, ${ }^{b}$ Fernanda Vitória Leimann, (D) a,c,d \\ Sara Marchesan de Oliveira, ${ }^{\mathrm{e}}$ Evelyne da Silva Brum, ${ }^{\mathrm{e}}$ Ricardo Costa Calhelha, ${ }^{\mathrm{C}}$ \\ Maria Filomena Barreiro, (D) c,d Isabel C. F. R. Ferreira, (D) *c Rafael Porto Ineu ${ }^{a}$ and \\ Odinei Hess Gonçalves (iD) a,c,d
}

\begin{abstract}
Beta-carotene is a carotenoid precursor of vitamin A, known for its biological activities. Due to its high hydrophobicity, nanonization processes, i.e. the transformation into nanoparticles, can improve its water affinity, and therefore the activity in aqueous systems. The objective of this study was to produce betacarotene nanoparticles by the solid dispersion method and to evaluate their effects on the activity of glutathione-S-transferase and acetylcholinesterase enzymes using Drosophila melanogaster (DM) homogenate, the superoxide dismutase- and catalase-like activities under in vitro conditions, and their cytotoxic properties against tumor and non-tumor cells. The formed nanometric beta-carotene particles resulted in stable colloids, readily dispersed in water, able to modulate acetylcholinesterase (AChE) activity, and presenting high potential to control the cholinergic system. Beta-carotene nanoparticles, at concentrations much lower than the pure pristine beta-carotene, presented in vitro mimetic activity to superoxide dismutase and altered glutathione-S-transferase activity in DM tissue. The content of hydrogen peroxide was neither affected by the nanoparticles (in aqueous solution) nor by pristine beta-carotene (in DMSO). In the cytotoxic assays, beta-carotene nanoparticles dispersed in water showed activity against four different tumor cell lines. Overall, beta-carotene nanoparticles presented significant bioactivity in aqueous medium surpassing their high hydrophobicity constraint.
\end{abstract}

\author{
Received 26th April 2018, \\ Accepted 13th June 2018 \\ DOI: $10.1039 / \mathrm{c} 8 \mathrm{fo} 00804 \mathrm{c}$ \\ rsc.li/food-function
}

\section{Introduction}

Beta-carotene is a carotenoid found in yellow-orange fruits and vegetables known for its antioxidant activity and as a precursor of vitamin A. $^{1,2}$ In the human body, beta-carotene inhibits cells' proliferation, modulates their differentiation, and acts in intracellular communications. The antioxidant activity of betacarotene may be explained by the neutralization of the oxyge-

\footnotetext{
${ }^{a}$ Post-Graduation Program of Food Technology (PPGTA), Federal University of Technology - Paraná - UTFPR, Campus Campo Mourão, via Rosalina Maria dos Santos, 1233, CEP 87301-899, Caixa Postal: 271, Campo Mourão, PR, Brazil ${ }^{b}$ Food Department (DALIM), Federal University of Technology - Paraná - UTFPR, Campus Campo Mourão, via Rosalina Maria dos Santos, 1233, CEP 87301-899, Caixa Postal: 271, Campo Mourão, PR, Brazil

${ }^{c}$ Centro de Investigação de Montanha (CIMO), Instituto Politécnico de Bragança, Campus Santa Apolónia, 5300-253 Bragança, Portugal.E-mail: iferreira@ipb.pt; Tel: +351273303219

${ }^{d}$ Laboratory of Separation and Reaction Engineering - Laboratory of Catalysis and Materials (LSRE-LCM), Polytechnic Institute of Bragança, Campus Santa Apolónia, 1134, 5300-253 Bragança, Portugal

${ }^{e}$ Graduate Program in Biological Sciences: Toxicological Biochemistry, Federal University of Santa Maria (UFSM), Avenida Roraima $n^{\circ} 1000$, 97105-900 Santa Maria, RS, Brazil
}

nated reactive species including free radicals, inhibiting their propagation and participation in peroxidative processes. Betacarotene has antioxidant activity at low partial oxygen pressure, prevalent in peripheral tissues. ${ }^{3-5}$ The relationship among carotenoids, oxidative stress, and inflammatory processes has been shown in different in vitro studies, especially those involving cellular models. ${ }^{6}$ Importantly, the consumption of bioactive compounds (exogenous source) is essential to maintain the redox state balance in the body. ${ }^{7}$

Beta-carotene is easily oxidized when exposed to air, light, and high temperatures. Also, its structure, composed of conjugated double bonds with a center of symmetry, results in a highly hydrophobic character. $^{8}$ Thus, technological approaches able to improve the bioavailability of beta-carotene and other carotenoids in hydrophilic media are required. ${ }^{9}$ Although several encapsulation methods are reported for betacarotene,${ }^{10-12}$ the solid dispersion technique has been used to increase solubility, oral absorption and dissolution rate of poor water-soluble drugs. ${ }^{13}$ It was demonstrated that when polyvinylpyrrolidone (PVP) is used, beta-carotene nanoparticles (also called nanocrystals) are formed and PVP acts as a protective colloid that can be removed depending on the required application. ${ }^{14}$ In fact, the production of a stable beta-carotene 
nanodispersion is still a work in progress. Physically stable nanodispersions of beta-carotene have been achieved, ${ }^{15}$ but chemical degradation may be an issue. ${ }^{16}$ Since beta-carotene presents remarkable bioactive properties and is also readily available in nature it is important to determine how the transformation in nanoparticles could influence beta-carotene bioactivity. Also, it is worth noting that nanoparticles usually present improved water affinity ${ }^{17}$ which may be of interest to obtain pharmaceutical formulations and also to produce water-based food colorants.

Superoxide dismutase (SOD), catalase (CAT) and glutathione- $S$-transferase (GST) are enzymes that play an important role in intracellular detoxification, protecting the organism against oxidative damage of cellular components, such as lipids, proteins and nucleic acids. SOD is part of the antioxidant biological defense mechanism and converts superoxide radicals into hydrogen peroxide. A deficiency in SOD activity has been related to human diseases such as amyotrophic lateral sclerosis, cancer, cataract and Parkinson's disease. ${ }^{18}$ CAT is present in all the living aerobic organisms and one of its function is to decompose hydrogen peroxide $\left(\mathrm{H}_{2} \mathrm{O}_{2}\right)$ into water and molecular oxygen, eliminating deleterious $\mathrm{H}_{2} \mathrm{O}_{2} \cdot{ }^{19}$ GST is an enzyme that plays an important role in the detoxification of xenobiotics and in the protection against oxidative stress. Classical in vivo studies demonstrate that the ingestion of beta-carotene is linked to increased levels of GSTrelated proteins. $^{20}$

Acetylcholine (ACh) is a neurotransmitter present in the nervous system, widely distributed throughout the brain, and at lower amounts in the cerebellum. The enzyme acetylcholinesterase (AChE) hydrolyzes acetylcholine into choline and acetate. $^{21}$ The capacity of bioactive compounds to modulate acetylcholinesterase is important because this enzyme is related to various diseases like Alzheimer's disease and to cognitive functions, such as memory. ${ }^{22}$

An alternative biological model to test the beta-carotene effects is Drosophila melanogaster (DM), which is widely used in biological tests due to its great similarity to the human genetic sequence, allowing the understanding of complex biological problems. ${ }^{19,23}$

Toxicity of beta-carotene has been investigated due to the use of beta-carotene as a dietary supplement. As stated by Sacha and co-workers, ${ }^{24}$ beta-carotene is able to inhibit the cell growth of tumor cells like lung, melanoma, colon and breast cancer. Beta-carotene demonstrated anti-apoptotic protection in the studies on bile acid-induced hepatotoxicity. ${ }^{25}$ The possible cytotoxic effects of beta-carotene degradation derivatives have also been investigated due to the instability of beta-carotene. ${ }^{26,27}$

The toxicity of encapsulated bioactive substances has been the subject of recent studies. Microencapsulated beta-carotene showed protective effects on the liver in in vivo experiments. ${ }^{12}$ Beta-carotene was encapsulated in various protein systems like sodium caseinate, whey protein isolate and soy protein isolate and the resulting nanoparticles presented low toxicity, which was attributed to the used encapsulants. ${ }^{11} \mathrm{Gu}$ et $a{ }^{10}{ }^{10}$ also demonstrated that beta-carotene-loaded emulsions only exhibited a slight cytotoxicity when used at high concentrations, evidencing that toxicity must be assessed after the encapsulation process.

The aim of the present study was to evaluate the capacity of beta-carotene nanoparticles to: (i) modulate GST and AChE activities using a DM homogenate; (ii) mimic SOD and CAT activities under in vitro conditions; and (iii) evaluate the cytotoxic properties on selected human tumor cell lines and nontumor cells.

\section{Materials and methods}

\subsection{Materials}

Beta-carotene (97\% purity, Sigma-Aldrich), polyvinylpyrrolidone (40000.00 g mol ${ }^{-1}$, Sigma-Aldrich, Brazil), Tween 80 (Dinâmica, Brazil) and ethanol (99.8\%, Neon, Brazil) were used to produce beta-carotene nanoparticles. Potassium bromide (KBr) (Sigma-Aldrich, spectroscopic standard) was used in Fourier transform infrared spectroscopy. 1-Chloro-2,4dinitrobenzene (CDNB), 5,5'-dithiobis (2-nitrobenzoic acid) (DTNB), reduced glutathione (GSH) and acetylthiocholine (Sigma-Aldrich) were used to determine glutathione- $S$-transferase (GST) and acetylcholinesterase (AChE) activities in in vitro assays. Adrenaline, catalase (CAT) from bovine liver (E.C.: 1.11.1.6; Lot: 81H7146) and superoxide dismutase (SOD) from bovine erythrocytes (E.C.:1.15.1.1 Lot: 98F-9310) were acquired from Sigma (Sigma Chemical Co., St Louis, USA). Dimethyl sulfoxide (DMSO) was acquired from Fisher Scientific (Lisbon, Portugal). Acetic acid, sulforhodamine B (SRB), trypan blue, trichloroacetic acid (TCA) and tris-(hydroxymethyl)aminomethane (TRIS) were purchased from Sigma (St Louis, MO, USA). Dulbecco's Modified Eagle's Medium (DMEM) and RPMI-1640 medium, fetal bovine serum (FBS), Hank's balanced salt solution (HBSS), L-glutamine, nonessential amino acid solution ( $2 \mathrm{mM}$ ), penicillin/streptomycin solution (100 $\mathrm{U} \mathrm{mL}^{-1}$ and $100 \mathrm{mg} \mathrm{mL}^{-1}$, respectively), trypsin, and EDTA (ethylenediaminetetraacetic acid) were acquired from Hyclone (Logan, UT, USA). Water was treated in a Milli-Q water purification system (TGI Pure Water Systems, Greenville, SC, USA) before use.

\subsection{Preparation of beta-carotene nanoparticles}

Nanoparticles were produced by the solid dispersion method, according to Silva and co-workers ${ }^{28}$ with minor modifications. Briefly, a surfactant (Tween 80, $75 \mathrm{mg}$ ) was diluted in ethanol (37.5 mL). After this, PVP (900 mg) and beta-carotene (90 mg) were added under magnetic stirring for 1 minute. The obtained solution was sonicated (Fisher Scientific, $120 \mathrm{~W}$ and $1 / 8^{\prime}$ tip) for 3 minutes, under pulse conditions of 30 seconds on and 10 seconds off. Finally, the solvent was evaporated at $60{ }^{\circ} \mathrm{C}$ for $24 \mathrm{~h}$. This formulation presented a betacarotene : PVP ratio of $1: 10(\mathrm{w}: \mathrm{w})$. 


\subsection{Nanoparticle characterization}

Transmission electron microscopy (TEM; JEOL model JEM 2100, $200 \mathrm{kV}$ ) was carried out with diluted samples dripped onto 300 mesh parlodium covered grids and dried at room temperature. Particle size distribution was determined by laser diffraction (Malvern Mastersizer 3000) using water as the dispersant. The parameters $D_{10}, D_{50}$ and $D_{90}$ were calculated from the cumulative size distribution in volume and correspond to the size comprising $10 \%, 50 \%$ and $90 \%$ microparticle's volume, respectively. The images of beta-carotene and nanoparticles dispersed in water at the same concentration $\left(1 \mathrm{mg} \mathrm{mL}{ }^{-1}\right)$ were obtained. Differential Scanning Calorimetry (DSC, PerkinElmer, DSC 4000) was used to evaluate the thermal properties of the nanoparticles. For this, the samples were poured into sealed aluminum pans under a nitrogen flow $\left(50 \mathrm{~mL} \mathrm{~min}{ }^{-1}\right.$ ) and heated from 0 to $300{ }^{\circ} \mathrm{C}$ at a heating rate of $20{ }^{\circ} \mathrm{C} \mathrm{min}^{-1}$. Fourier transform infrared (FTIR, Shimadzu, IRAffinity-1S) spectra were acquired in transmittance mode (i.e. using potassium bromide pellets), with a resolution of $2 \mathrm{~cm}^{-1}$ from 4500 to $500 \mathrm{~cm}^{-1}$ by co-adding 32 scans. X-ray diffraction (DRX) analysis (XRD, Bruker, D8 Advance) was carried out from $3^{\circ}$ to $60^{\circ}(2 \theta)$ at $5.9^{\circ} \mathrm{min}^{-1}$, using $\mathrm{Ku} \mathrm{C} \alpha$ radiation generated at $40 \mathrm{kV}$ and $35 \mathrm{~mA}$.

For DSC and FTIR, PVP was removed from the beta-carotene nanoparticle dispersion. The dried nanoparticles were dispersed in water and vortexed for 1 minute; then they were centrifuged at $14000 \mathrm{rpm}$ for 30 minutes. The supernatant was discharged, and the procedure repeated 4-fold. The absence of PVP was attested by FTIR. DRX analysis was carried out with unwashed particles due to the high amount of sample demanded by the technique.

\subsection{Enzymatic assays}

In vitro enzymatic assays were performed with a beta-carotene nanoparticle concentration ranging from 1 to $400 \mu \mathrm{M}$. The mimetic effects of pristine beta-carotene dispersed in water were also evaluated on the enzymes' activity. Drosophila melanogaster (DM) wild-type flies were obtained from the National Species Stock Center (Bowling Green, OH, USA). The flies were maintained in cornmeal medium at constant temperature and humidity (22-24 ${ }^{\circ} \mathrm{C}$; 45-65\% relative humidity) under $12 \mathrm{~h}$ dark/light cycle conditions. A total of five hundred adult flies, both gender, were numbed in a domestic freezer and manually homogenized in $5000 \mu \mathrm{L}$ of Tris- $\mathrm{HCl}$ solution ( $50 \mathrm{mM}, \mathrm{pH} 7.0$ ). After this, the samples were centrifuged at $12000 \mathrm{rpm}$ for 10 minutes. The protein content was measured according to Bradford (1976). ${ }^{29} 50 \mu \mathrm{L}$ of the homogenized flies were added to $2.5 \mathrm{~mL}$ of Coomassie blue. After 10 minutes, the concentration of proteins was determined by ultraviolet-visible spectroscopy (UV-Vis, Ocean Optics, Red Tide USB650) at $595 \mathrm{~nm}$ using bovine serum albumin as standard (calibration curves previously obtained from 0.01 to $0.05 \mathrm{mg} \mathrm{mL}^{-1}$ ). The results are expressed as $\mathrm{mg} \mathrm{mL}^{-1}$.

The glutathione- $S$-transferase (GST) activity was assessed according to the method described by Habig and co-workers ${ }^{30}$ using 1-chloro-2,4-dinitrobenzene (CDNB). A solution containing $520 \mu \mathrm{L}$ of distilled water, $400 \mu \mathrm{L}$ of potassium phosphate buffer (100 mM, pH 7.5), $50 \mu \mathrm{L}$ of DM homogenate and $10 \mu \mathrm{L}$ of an aqueous dispersion of nanoparticles was incubated for 2 minutes at room temperature. Afterwards, $10 \mu \mathrm{L}$ of reduced glutathione $(100 \mathrm{mM})$ and $10 \mu \mathrm{L}$ of CDNB $(100 \mathrm{mM})$ were added to the solution and the absorbance was measured by UV-Vis at $340 \mathrm{~nm}$, every 30 seconds, for a total time of 4 minutes. GST activity was calculated using a molar extinction coefficient of $9.6 \mathrm{M}^{-1} \mathrm{~cm}^{-1}$ and normalized in the graphics to percentage of the control.

AChE activity was evaluated according to a previous study ${ }^{31}$ with minor modifications. A solution containing $600 \mu \mathrm{L}$ of distilled water, $100 \mu \mathrm{L}$ of Tris- $\mathrm{HCl}(50 \mathrm{mM}, \mathrm{pH} 7.4), 100 \mu \mathrm{L}$ of 5,5'dithiobis(2-nitrobenzoic acid) (DTNB) (5 mM), $75 \mu \mathrm{L}$ of DM homogenate, and $25 \mu \mathrm{L}$ of an aqueous dispersion of beta-carotene nanoparticles $(1-400 \mu \mathrm{M})$ was incubated for $2 \mathrm{~min}$ at $22{ }^{\circ} \mathrm{C}$. $75 \mu \mathrm{L}$ of acetylthiocholine $(8 \mathrm{mM})$ were added to the solution and the absorbance was measured by UV-Vis at $420 \mathrm{~nm}$, every 30 seconds, for a total time of 3 minutes with an absorption coefficient of $0.0136 \mathrm{M}^{-1} \mathrm{~cm}^{-1}$ for the TNB anion. Enzymatic activity was calculated as $\mu \mathrm{mol}$ of hydrolyzed substrate per min per $\mathrm{mg}$ of protein and normalized to percentage of the control.

The scavenging activity of the pristine beta-carotene and of the beta-carotene nanoparticles against the superoxide anion was assessed as described in the literature. ${ }^{32}$ The SOD-like activity was quantified by the inhibition of superoxide-dependent adrenaline auto-oxidation to adrenochrome, a yellow chromophore. Beta-carotene (1-100 $\mu \mathrm{M}$; solubilized in 3.33\% DMSO), beta-carotene (1-100 $\mu \mathrm{M}$; solubilized in $\left.\mathrm{H}_{2} \mathrm{O}\right)$, betacarotene-PVP nanoparticles (1-100 $\mu \mathrm{M}$; solubilized in $\mathrm{H}_{2} \mathrm{O}$ ), PVP $\left(12 \mu \mathrm{M}\right.$; solubilized in $\left.\mathrm{H}_{2} \mathrm{O}\right)$ and used vehicles $(3.33 \%$ DMSO and distilled $\mathrm{H}_{2} \mathrm{O}$ ) were incubated with sodium carbonate buffer $(50 \mathrm{mM}, \mathrm{pH} 10.2)$ at $30{ }^{\circ} \mathrm{C}$. The reaction was initiated by the addition of adrenaline ( $60 \mathrm{mM}, \mathrm{pH} 2.0)$, with the reactive mixture kept on ice and protected from light, over the reaction time. The scavenging activity was determined spectrophotometrically at $480 \mathrm{~nm}$ in kinetic mode for 2 minutes. The area under the curve (AUC) of adrenochrome produced a linear region that was used for the statistical analysis and compared against the control values (auto-oxidation). The final results were expressed as AUC of adrenaline auto-oxidation percentage (\%). The units of SOD (5-10 U) (E.C.: 1. 15. 1. 1) were used to determine the assay specificity.

In order to assess the in vitro beta-carotene reactivity against $\mathrm{H}_{2} \mathrm{O}_{2}$, the methodology described by Oliveira and coworkers $^{32}$ and Ruch and co-workers ${ }^{33}$ was used. Beta-carotene (1-100 $\mu \mathrm{M}$; solubilized in $0.5 \%$ DMSO), beta-carotene (1-100 $\mu \mathrm{M}$; solubilized in PBS), beta-carotene-PVP nanoparticles (1-100 $\mu \mathrm{M}$; solubilized in PBS), PVP $(12 \mu \mathrm{M}$; solubilized in PBS) and used vehicles (0.5\% DMSO and PBS $0.1 \mathrm{M}$, $\mathrm{pH}$ 7.4) were incubated with $13 \mathrm{mM} \mathrm{H}_{2} \mathrm{O}_{2}$ for $2 \mathrm{~min}$. After the incubation period, $\mathrm{H}_{2} \mathrm{O}_{2}$ absorbance was determined spectrophotometrically at $230 \mathrm{~nm}$ against a blank (solutions without $\mathrm{H}_{2} \mathrm{O}_{2}$ ). The remaining concentration of $\mathrm{H}_{2} \mathrm{O}_{2}$ was calculated 
using a molar extinction coefficient of $81 \mathrm{M}^{-1} \mathrm{~cm}^{-1}$. Five units of CAT (E.C.: 1. 11. 1. 6) were used to determine the assay specificity.

\subsection{Cytotoxic assays}

Pristine beta-carotene was dissolved in a DMSO/water mixture $(1: 1, \mathrm{v} / \mathrm{v})$ at a concentration of $8 \mathrm{mg} \mathrm{L}^{-1}$, since it is insoluble in water. Beta-carotene nanoparticles were dispersed in water also at a concentration of $8 \mathrm{mg} \mathrm{mL} \mathrm{m}^{-1}$. Successive dilutions were thereafter prepared from these stock solutions. MCF-7 (breast adenocarcinoma), NCI-H460 (non-small cell lung carcinoma), HeLa (cervical carcinoma) and HepG2 (hepatocellular carcinoma) from DSMZ (Leibniz-Institut DSMZ-Deutsche Sammlung von Mikroorganismen und Zellkulturen $\mathrm{GmbH}$ ) were selected as human tumor cell lines. To assess the cytotoxicity of the samples, the sulforhodamine (SRB) assay was performed according to a procedure previously described by Abreu et $a l .{ }^{34}$ For toxicity evaluation toward porcine liver cells, a primary cell culture was prepared according to a procedure previously established by Abreu et al. ${ }^{34}$ These cells (PLP2) were treated for $48 \mathrm{~h}$ with the different sample solutions and the SRB assay was followed. ${ }^{35}$ The results were expressed as $\mathrm{GI}_{50}$ values (concentrations that inhibited $50 \%$ of the net cell growth). Ellipticine was used as a standard. For these experiments, beta-carotene nanoparticles were washed with distilled water in order to remove PVP as described in section 2.3.

\subsection{Statistical analysis}

Statistical analysis of the results was performed using the software GraphPad Prism version 6.0 (Graph Pad, USA). The data obtained in the enzymatic assays are expressed as mean \pm SEM (standard error of the mean) in percentage of the control. The scavenging activity results were expressed as means \pm SEM, except for the $\mathrm{IC}_{50}$ values (i.e., the concentration that reduces adrenaline auto-oxidation or $\mathrm{H}_{2} \mathrm{O}_{2}$ levels to the order of $50 \%$ relative to the control value), which were expressed as geometric means accompanied by their respective 95\% confidence limits. The results of cytotoxic properties are expressed as mean $\pm \mathrm{SD}$ (standard deviation of the mean). One-way
ANOVA followed by Tukey's post hoc test was carried out for enzymatic studies; differences were considered significant at values of $P<0.05$. The cytotoxic results were compared by Student's $t$-test with $5 \%$ significance.

\section{Results and discussion}

\subsection{Nanoparticle characterization}

Fig. 1 shows the TEM images of the produced beta-carotene nanoparticles, the corresponding particle size distributions and the visual aspect of the beta-carotene nanoparticle and pristine beta-carotene dispersions in water. Fig. 2 shows the obtained DSC thermograms, infrared spectra and DRX patterns of beta-carotene, PVP and beta-carotene nanoparticles. Physical mixtures (PM) were also produced by manually mixing PVP and beta-carotene (weight proportions PVP : betacarotene of $2: 1,5: 1,10: 1$ and $15: 1$ ) and analyzed, in order to compare with the nanoparticles. Table 1 presents the determined enthalpy values obtained from the endothermic peaks of beta-carotene nanoparticles, beta-carotene, PVP and the produced physical mixtures.

The nanoparticles were readily dispersible in water forming a stable colloidal system. As expected, beta-carotene could not be efficiently dispersed in water due to its high hydrophobicity putting in evidence the advantages of the applied nanonization process. The values found for particle sizes $D_{10}, D_{50}$ and $D_{90}$ were $0.337 \pm 0.050,0.439 \pm 0.045$ and $0.602 \pm 0.074 \mu \mathrm{m}$, respectively. In the work of Silva and co-workers ${ }^{28}$ an average size of $200 \mathrm{~nm}$ was found for the lutein-loaded PVP nanoparticles produced by the solid dispersion method. The nanometric size was also corroborated by TEM images, with particles presenting no spherical shape, as it is typical of crystalline materials.

The infrared absorption pattern was similar to the one found in the literature for beta-carotene. ${ }^{36-38}$ It is possible to identify the characteristic absorption bands at $2913 \mathrm{~cm}^{-1}$ and $2950 \mathrm{~cm}^{-1}$, corresponding to the symmetric and asymmetric stretching of $\mathrm{CH}_{2}$, respectively. The peaks at $959-953 \mathrm{~cm}^{-1}$ (a)

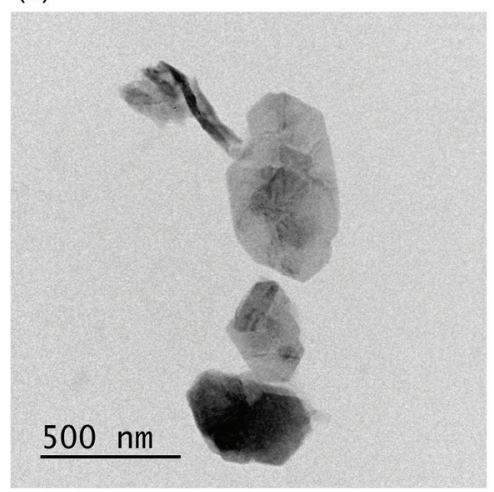

(b)

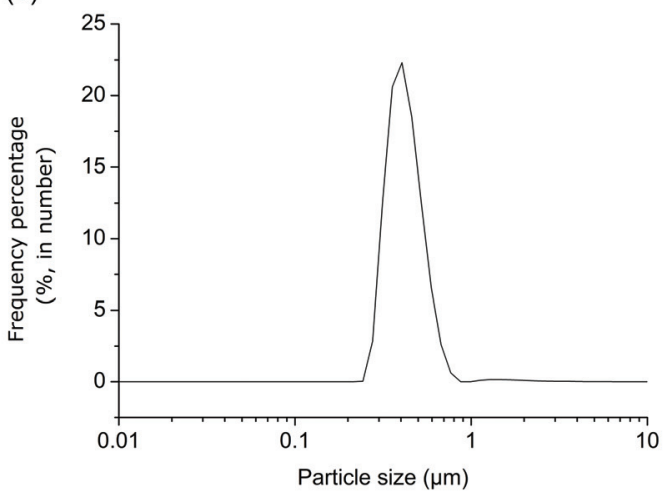

(c)

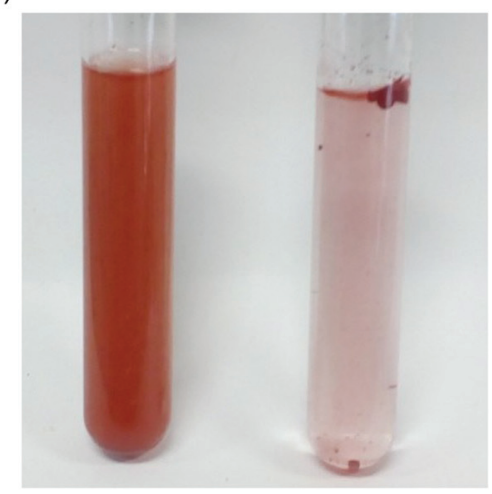

Fig. 1 Results of the nanoparticle characterization: (a) transmission electron microscopy images; (b) particle size distribution; and (c) images of the aqueous dispersions containing beta-carotene and the produced nanoparticles. 
(a)

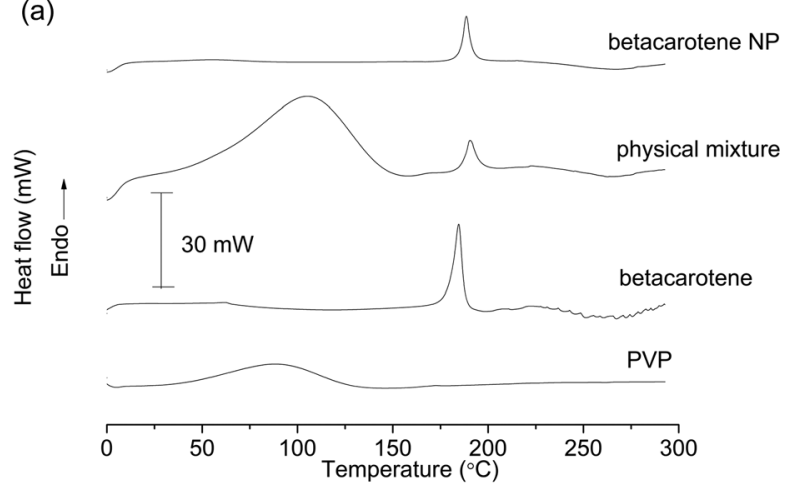

(c)

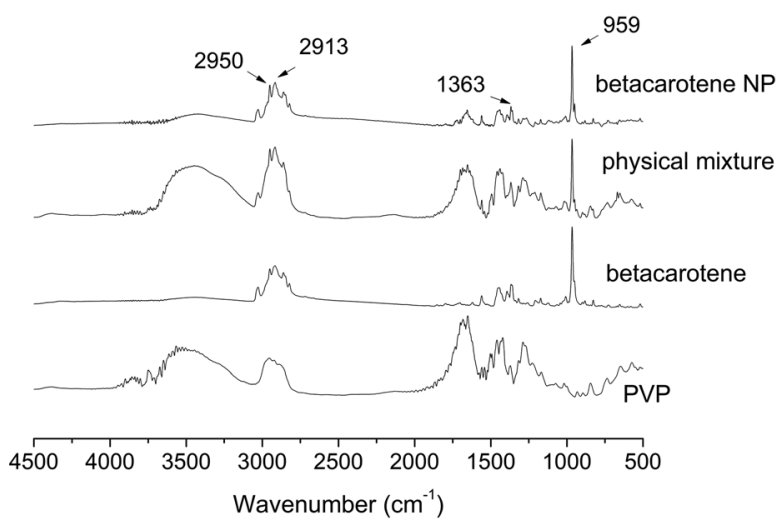

(b)
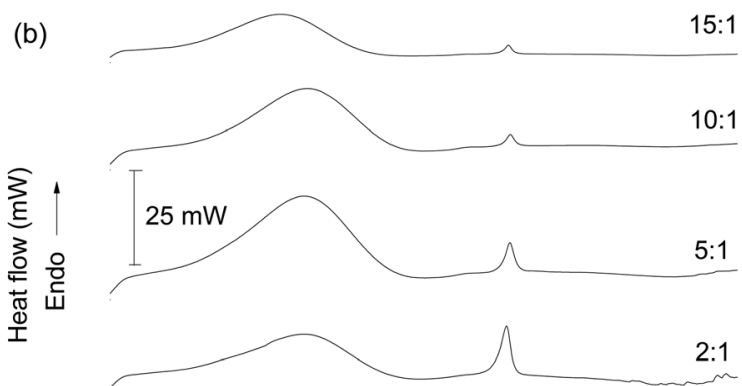

$10: 1$

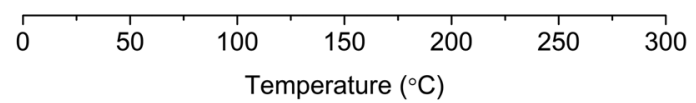

(d)
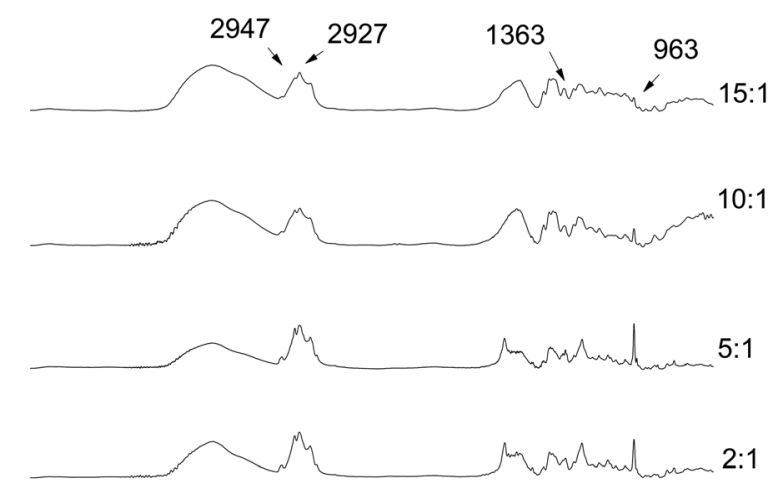

$\begin{array}{llllllllll}4500 & 4000 & 3500 & 3000 & 2500 & 2000 & 1500 & 1000 & 500\end{array}$

Wavenumber $\left(\mathrm{cm}^{-1}\right)$

(e)
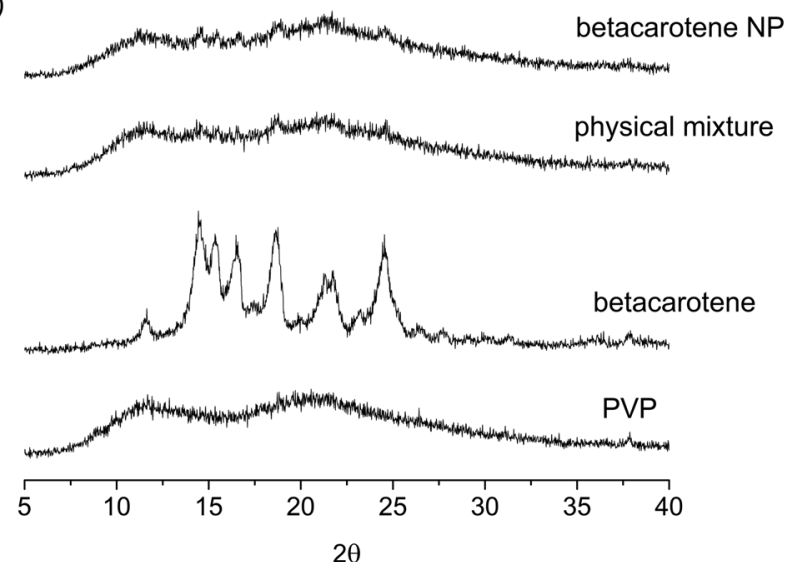

$2 \theta$

Fig. 2 Results of the nanoparticle characterization: (a) and (b) DSC thermograms; (c) and (d) FTIR spectra; and (e) XRD patterns.

represent the conjugated alkene. Finally, the band at $1363 \mathrm{~cm}^{-1}$ corresponds to the $\beta$-ionone rings of betacarotene. ${ }^{36}$ For the physical mixture, the intensity of the beta-carotene characteristic peaks increased with increasing beta-carotene concentration. No differences were found between the nanoparticles and the pristine beta-carotene meaning that the transformation into nanoparticles did not change the chemical structure of beta-carotene and that no interaction between it and PVP is expected to occur.

The DSC thermograms showed endothermic peaks at 184.6 ${ }^{\circ} \mathrm{C}$ for pristine beta-carotene and at $188.6^{\circ} \mathrm{C}$ for the nanoparticles, which is related to the crystalline melting transition. This peak was also observed in the analysis of the physical mixtures, becoming more intense as the beta-carotene 
Table 1 Melting temperature and enthalpy of the beta-carotene-PVP nanoparticles

\begin{tabular}{llr}
\hline Compound & $\Delta H\left(\mathrm{~J} \mathrm{~g}^{-1}\right)$ & $T\left({ }^{\circ} \mathrm{C}\right)$ \\
\hline Beta-carotene & 103.9 & 184.6 \\
PVP & 174.6 & 88.6 \\
Nanoparticles & 158.9 & 188.6 \\
Physical mixture $2: 1(\mathrm{~m}: \mathrm{m})$ & 167.1 & 185.1 \\
Physical mixture $5: 1(\mathrm{~m}: \mathrm{m})$ & 231.6 & 186.6 \\
Physical mixture $10: 1(\mathrm{~m}: \mathrm{m})$ & 178.1 & 187.7 \\
Physical mixture $15: 1(\mathrm{~m}: \mathrm{m})$ & 212.4 & 188.1
\end{tabular}

content increases, suggesting that a simple mixture of the components was attained with no further interactions between both components (beta-carotene and PVP). ${ }^{28,37}$ PVP does not show any melting peak, a fact compatible with its amorphous nature. ${ }^{39}$ The broad endothermic peak shown at around $88{ }^{\circ} \mathrm{C}$ is often related to residual moisture evaporation. ${ }^{28}$ The comparison between the DSC thermograms of physical mixtures and nanoparticles suggests that the crystalline structure of beta-carotene did not change after its nanonization, which is also in accordance with the conclusions drawn from the FTIR and TEM results.

The XRD pattern of pristine beta-carotene showed strong peaks between 13 and $25^{\circ}$, indicating the crystalline structure of beta-carotene. Most of these peaks were attenuated in the nanoparticle's XRD sample, and in the physically produced mixture, observation associated with the low beta-carotene concentration. $^{37}$ Despite this fact, the patterns of both samples did not differ significantly suggesting that both samples have a similar crystalline state.

In conclusion, the preformed characterization analyses strongly suggest that the transformation of beta-carotene into nanoparticles was successful and that beta-carotene remained crystalline after nanonization. Also, no strong interaction between PVP and beta-carotene was found which may be explained by the chemical structure of beta-carotene itself. The nanoparticles were colloidally stable when dispersed in water which makes their application viable in aqueous systems without the use of organic solvents, thus emulating actual biosystems.

\subsection{Enzymatic studies}

Fig. 3 shows the results of acetylcholinesterase enzyme (AChE) activity in Drosophila Melanogaster tissue in the presence of pristine beta-carotene and beta-carotene nanoparticles dispersed in water.

It is known that the modulation of cholinesterase enzymes, like AChE, is involved in neurodegenerative diseases, motor function, and locomotion. AChE is an essential enzyme of the nervous system where the cholinergic transmission of impulses occurs. Thus, inhibition of AChE results in the accumulation of acetylcholine causing overstimulation of the acetylcholine receptors, compromising the normal motor activity of the flies. ${ }^{40}$ Beta-carotene nanoparticles (300 and $400 \mu \mathrm{M})$ decreased the acetylcholinesterase enzyme activity

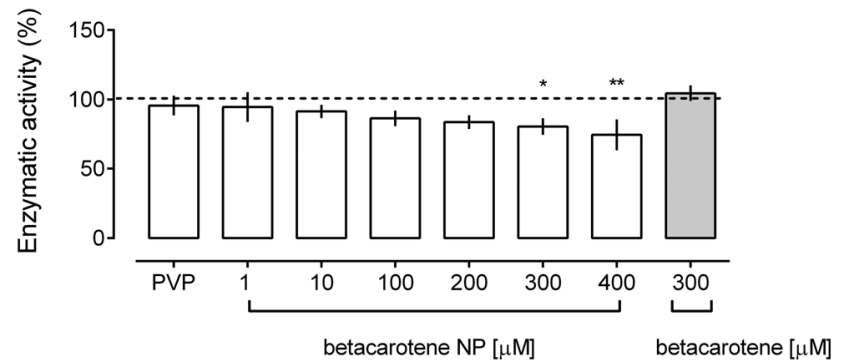

Fig. 3 Effects of beta-carotene nanoparticles (concentration of 1-400 $\mu \mathrm{M})$ and beta-carotene $(300 \mu \mathrm{M})$ on acetylcholinesterase (AChE) enzyme activity in Drosophila melanogaster tissue. PVP $=4.02 \mu \mathrm{M}$. Values are mean \pm SEM ( $n=4$ per group). Significance determined by one-way analyses of variance (ANOVA) followed by Tukey's test. * $p<$ $0.05 ;{ }^{* *} p<0.01$ both in comparison with the control.

( $p<0.05$ and $p<0.0001$, respectively). Pristine beta-carotene was also tested at $300 \mu \mathrm{M}$, the lowest concentration at which beta-carotene nanoparticles presented biological activity. In this case, no activity was detected; it should be emphasized that pristine beta-carotene at $300 \mu \mathrm{M}$ is not soluble in water. The literature reporting the influence of beta-carotene on the acetylcholinesterase activity is scarce. Nevertheless, the work of Lebda et al $^{41}$ reported a decrease of AChE levels in rats daily treated with a lycopene dosage of $10 \mathrm{mg} \mathrm{kg}^{-1}$ for 20 days, after exposure to high doses of manganese $\left(6 \mathrm{mg} \mathrm{kg}^{-1}\right)$ for 4 weeks.

Fig. 4 presents the results of glutathione- $S$-transferase (GST) activity in the presence of pristine beta-carotene and beta-carotene nanoparticles dispersed in water.

Beta-carotene nanoparticles caused a significant increase of glutathione- $S$-transferase activity $(p<0.05)$ at final concentrations of 1,10 and $30 \mu \mathrm{M}$ while at concentrations of 200 to $400 \mu \mathrm{M}$ a decrease in activity was observed. Pristine beta-carotene was evaluated at concentrations of 30 and $300 \mu \mathrm{M}$, and no change in GST activity (increase or decrease) was detected, also justified due to the beta-carotene insolubility in water. The presented results are in accordance with the data reported in the literature. Dhingra and Bansal ${ }^{42}$ observed an increase in gluta-

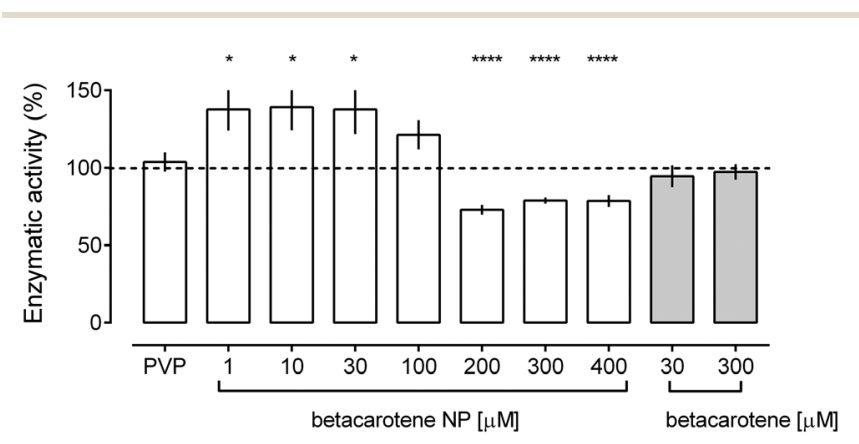

Fig. 4 Effects of beta-carotene nanoparticles (1-400 $\mu \mathrm{M})$ and betacarotene $(30-300 \mu \mathrm{M})$ on glutathione-S-transferase (GST) activity in Drosophila melanogaster tissue. PVP $=4.02 \mu \mathrm{M}$. Values are mean $\pm \mathrm{SEM}$ ( $n=6-8$ per group). Significance determined by one-way analyses of variance (ANOVA) followed by Tukey's test. ${ }^{*} p<0.05$; ${ }^{* * *} p<0.0001$ both in comparison with the control. 
thione levels in mice treated with doses of 50 to $100 \mathrm{mg} \mathrm{kg}^{-1}$ of beta-carotene. Novo et al. ${ }^{43}$ also observed an increase in the rate relation of reduced glutathione (GSH)/oxidized glutathione (GSSG) in the heart and liver of rats, with a daily dosage of $500 \mathrm{mg} \mathrm{kg}^{-1}$ of beta-carotene. Also, McGill and co-workers ${ }^{44}$ evaluated the effects of a daily dosage of $30 \mathrm{mg}$ of beta-carotene for 60 days in humans, and observed a significant decrease of glutathione peroxidase activity. According to the authors, this decrease could be justified by the antioxidant activity in the organism, becoming able to modify the in vivo antioxidant capacity of cells present in plasma and blood. In vitro and in vivo studies by Li et al. ${ }^{45}$ demonstrated strong evidence that GST inhibitor modified prodrugs combined with nanoparticles significantly enhanced antitumor effects against cisplatin-resistant cancer.

Fig. 5 presents the scavenging effects on superoxide anions and Fig. 6 presents the scavenging effects of the pristine betacarotene and beta-carotene nanoparticles dispersed in water on hydrogen peroxide.

A significant superoxide anion scavenging activity was observed with beta-carotene nanoparticles $(p<0.001)$ at concentrations of 1,10 and $100 \mu \mathrm{M}$. The beta-carotene nano-

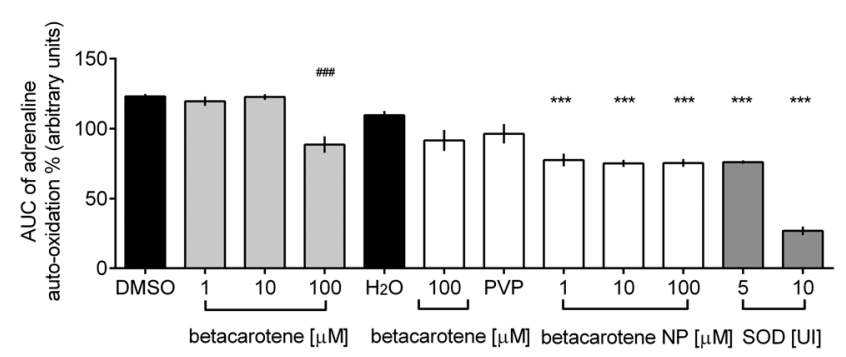

Fig. 5 Superoxide anion scavenging activity of beta-carotene nanoparticles $(1-100 \mu \mathrm{M})$ and beta-carotene $(1-100 \mu \mathrm{M})$. PVP $=12 \mu \mathrm{M}$. Values are mean \pm SEM ( $n=6-8$ per group). Significance determined by one-way analyses of variance (ANOVA) followed by Tukey's test. ${ }^{* * *} p<$ 0.001 in comparison with the vehicle water; \#\#\#p<0.001 in comparison with the vehicle DMSO. White bars: activity measured in water; gray bars: activity measured in DMSO; and black bars: control. AUC: area under the curve; SOD: superoxide dismutase.

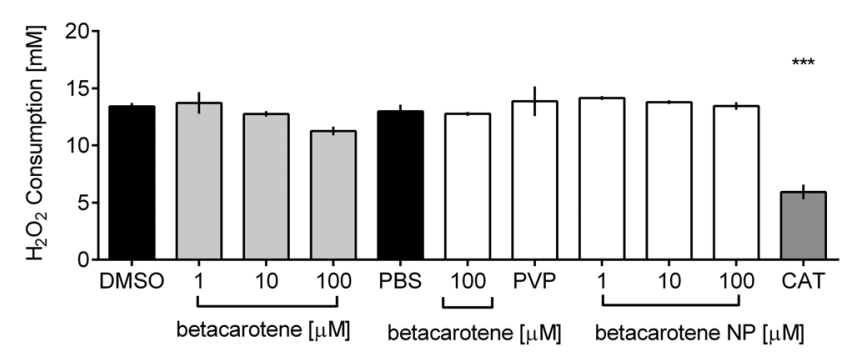

Fig. 6 Hydrogen peroxide scavenging activity of beta-carotene nanoparticles $(1-100 \mu \mathrm{M})$ and PVP $=12 \mu \mathrm{M}$. Values are mean \pm SEM $(n=6-8$ per group). Significance determined by one-way analyses of variance (ANOVA) followed by Tukey's test. ${ }^{* * *} p<0.001$ in comparison with PBS. White bars: activity measured in water; gray bars: activity measured in DMSO; and black bars: control. CAT: catalase. particle activity was very similar to the action found with SOD (5 UI), confirming their potent scavenging effect on superoxide anions, meaning that beta-carotene could have a mimetic SOD activity in defense against oxidative stress. For pristine betacarotene, the activity was significant only at a concentration of $100 \mu \mathrm{M}$, which demonstrates that nanonization of beta-carotene was efficient in improving its activity in aqueous solution. Blakely et $a .^{46}$ also observed a significant reduction of SOD activity in rats treated with high levels (10-fold higher than the recommended levels) of beta-carotene for 6 weeks. McGill et $a$. $^{44}$ evaluated the effects of a daily dosage of $30 \mathrm{mg}$ of betacarotene for 60 days in humans and observed a significant decrease of superoxide dismutase. According to the authors, the decrease could be due to the antioxidant activity exerted by the compound in the organism, able to modify the in vivo antioxidant capacity of cells present in plasma and blood.

Pristine beta-carotene has no CAT-like activity and the nanonization of beta-carotene was not able to modify its inactivity in scavenging $\mathrm{H}_{2} \mathrm{O}_{2}$. In fact, there were no significant differences in the scavenging $\mathrm{H}_{2} \mathrm{O}_{2}$ activity of pristine and beta-carotene nanoparticles. The results are in accordance with McGill and co-workers, ${ }^{44}$ who described that a daily supplementation of $30 \mathrm{mg}$ of beta-carotene for 60 days in humans did not affect the catalase activity. Blakely et $a l^{46}$ also did not observe any significant difference in catalase activity in rats treated with high levels (10-fold higher than the recommended levels) of beta-carotene for 6 weeks. Except for the case of CATlike activity (because beta-carotene has no inherent action on this system), beta-carotene nanoparticles presented improved activity when compared to the pristine beta-carotene form. In fact, due to its high hydrophobicity, beta-carotene is usually evaluated in solvents such as DMSO. However, it is important to compare its activity in aqueous systems to better evaluate the influence of the nanonization procedure. The higher surface area of the nanoparticles when compared with micrometric formulations leads to improved colloidal stability in water when compared to pristine beta-carotene. ${ }^{37}$

\subsection{Cytotoxic properties}

Table 2 presents the results regarding the cytotoxic properties of beta-carotene nanoparticles dispersed in water and pristine beta-carotene.

The assays using pristine beta-carotene were performed in DMSO while water was used in the case of the nanoparticles. This is important because beta-carotene is highly water insoluble. It was not possible to carry out the experiments using pristine beta-carotene in water due to its precipitation in water medium and the consequent lack of activity. Both samples (pristine beta-carotene and beta-carotene nanoparticles) presented cytotoxic effects against all the selected tumor cell lines in a relatively low concentration when compared to other hydrophobic bioactive compounds. ${ }^{47}$ Statistical differences between the nanoparticles and pristine beta-carotene were only observed in MCF7 and HepG2 cell lines. Toxicity to normal cells (PLP2) was also observed but without statistical differences among both samples. Moreover, values found in 
Table 2 Cytotoxic properties of beta-carotene and beta-carotene nanoparticles dispersed in water

\begin{tabular}{llllll}
\hline & \multicolumn{2}{l}{ Cytotoxic properties $\left(\mathrm{GI}_{50}\right.$ values, $\left.\mu \mathrm{g} \mathrm{mL}^{-1}\right)$} & & \\
\cline { 2 - 6 } & MCF7 & NCI-H460 & HepG2 & HeLa & PLP2 \\
\hline Beta-carotene & $42.72 \mathrm{a} \pm 2.31$ & $44.47^{\mathrm{a}} \pm 1.26$ & $27.76^{\mathrm{a}} \pm 0.45$ & $24.13^{\mathrm{a}} \pm 1.40$ & $177.91^{\mathrm{a}} \pm 13.39$ \\
Beta-carotene nanoparticles & $60.65^{\mathrm{b}} \pm 1.12$ & $48.93^{\mathrm{a}} \pm 0.87$ & $39.98^{\mathrm{b}} \pm 1.61$ & $31.68^{\mathrm{a}} \pm 2.73$ & $229.18^{\mathrm{a}} \pm 16.83$
\end{tabular}

${ }^{\mathrm{a}, \mathrm{b}}$ Values in a column with different letters are significantly different $(p<0.05)$ by Student's $t$-test.

non-tumor cells were much higher than the concentration needed to exert $50 \%$ of activity against tumor cell lines.

\section{Conclusion}

Beta-carotene nanoparticles were obtained by a process called nanonization in which pristine beta-carotene is stabilized with polyvinylpyrrolidone (PVP). Physicochemical analyses demonstrated that the particles were colloidally stable in water and composed of beta-carotene with PVP as a protective colloid. In vitro assays were carried out to determine if beta-carotene nanoparticles dispersed in water were able to modulate acetylcholinesterase (AChE) and glutathione- $S$-transferase (GST), and if they present enzymatic activity mimetic to superoxide dismutase (SOD) and catalase (CAT). Beta-carotene nanoparticles, but not pristine beta-carotene, at the same concentration $(300 \mu \mathrm{M})$, decreased D. melanogaster AChE activity, while betacarotene nanoparticles enhanced GST activity at low concentrations and reduced it at high concentrations. Neither betacarotene nanoparticles nor pristine beta-carotene were able to act like CAT, as in accordance with the literature data. On the other hand, beta-carotene nanoparticles displayed enhanced scavenging superoxide anion capacity, such as SOD, since this activity was detected at a lower concentration for nanoparticles. The results are relevant because beta-carotene nanoparticles could offer protection against cellular damage in the body, and therefore potentiate its endogenous antioxidant defense systems (GST, SOD and CAT are involved in the endogenous antioxidant system of the body). Nanoparticles dispersed in water also presented cytotoxic properties against tumor cell lines, which is a quite interesting result since betacarotene in its native form is highly hydrophobic. The results gathered demonstrate that the performance of beta-carotene in aqueous medium was highly improved when its nanoparticulate form was used allowing its biological activity to be exerted.

\section{Conflicts of interest}

There are no conflicts to declare.

\section{Acknowledgements}

The authors thank CNPq, CAPES and Fundação Araucária for the support. The authors are also grateful to the Foundation for Science and Technology (FCT, Portugal) for financial support to CIMO (strategic project UID/AGR/00690/2013) and R. Calhelha contract, and to the project POCI-01-0145FEDER-006984 - Associate Laboratory LSRE-LCM funded by the FEDER through COMPETE2020 - Programa Operacional Competitividade e Internacionalização (POCI) - and by national funds through FCT. This work was also funded by the European Structural and Investment Funds (FEEI) through the Regional Operational Program North 2020, within the scope of Project NORTE-01-0145-FEDER-023289: DeCodE and Project Mobilizador ValorNatural®.

\section{References}

1 D. B. Rodriguez-Amaya, J. Food Compos. Anal., 2010, 23, 726-740.

2 R. Elliott, Biochim. Biophys. Acta, Mol. Basis Dis., 2005, 1740, 147-154.

3 N. I. Krinsky, Nutrition, 2001, 17, 815-817.

4 M. Valko, D. Leibfritz, J. Moncol, M. T. D. Cronin, M. Mazur and J. Telser, Int. J. Biochem. Cell Biol., 2007, 39, 44-84.

5 M. Rutkowski and K. Grzegorczyk, Int. J. Occup. Med. Environ. Health, 2012, 25, 105-121.

6 A. Kaulmann and T. Bohn, Nutr. Res., 2014, 34, 907-929.

7 A. C. Kaliora, G. V. Z. Dedoussis and H. Schmidt, Atherosclerosis, 2006, 187, 1-17.

8 Y. Kohno, Y. Kato, M. Shibata, C. Fukuhara, Y. Maeda, Y. Tomita and K. Kobayashi, Microporous Mesoporous Mater., 2016, 220, 1-6.

9 I. D. Nwachukwu, C. C. Udenigwe and R. E. Aluko, Trends Food Sci. Technol., 2016, 49, 74-84.

10 L. Gu, C. Pan, Y. Su, R. Zhang, H. Xiao, D. J. McClements and Y. Yang, J. Agric. Food Chem., 2018, 66, 1649-1657.

11 J. Yi, T. I. Lam, W. Yokoyama, L. W. Cheng and F. Zhong, J. Agric. Food Chem., 2014, 62, 1096-1104.

12 A. F. Aissa, M. L. P. Bianchi, J. C. Ribeiro, L. C. Hernandes, A. F. de Faria, A. Z. Mercadante and L. M. G. Antunes, Food Chem. Toxicol., 2012, 50, 1418-1424.

13 S. Sareen, L. Joseph and G. Mathew, Int. J. Pharm. Invest., 2012, 2, 12.

14 T. Tachibana and A. Nakamura, Kolloid Z. Z. Polym., 1965, 203, 130-133.

15 H. D. Silva, M. A. Cerqueira, B. W. S. Souza, C. Ribeiro, M. C. Avides, M. A. C. Quintas, J. S. R. Coimbra, 
M. G. Carneiro-Da-Cunha and A. A. Vicente, J. Food Eng., 2011, 102, 130-135.

16 Y. Yuan, Y. Gao, J. Zhao and L. Mao, Food Res. Int., 2008, 41, 61-68.

17 M. Almeida, B. A. Rocha, C. R. L. Francisco, C. G. Miranda, P. D. F. Santos, P. H. H. De Araújo, C. Sayer, F. V. Leimann, O. H. Gonçalves and C. A. Bersani-Amado, Food Funct., 2018, 9, 440-449.

18 M. L. Doran, J. M. Knee, N. Wang, T. Z. Rzezniczak, T. L. Parkes, L. Li and T. J. S. Merritt, Free Radicals Biol. Med., 2017, 113, 323-334.

19 U. B. Pandey and C. D. Nichols, Drug Delivery, 2011, 63, 411-436.

20 E. van Lieshout, M. M. G. Bedaf, M. Pieter, C. Ekkel, W. A. Nijhoff and W. H. M. Peters, Carcinogenesis, 1998, 19, 2055-2057.

21 B. Vinutha, D. Prashanth, K. Salma, S. L. Sreeja, D. Pratiti, R. Padmaja, S. Radhika, A. Amit, K. Venkateshwarlu and M. Deepak, J. Ethnopharmacol., 2007, 109, 359-363.

22 Q. Li, H. Yang, Y. Chen and H. Sun, Eur. J. Med. Chem., 2017, 132, 294-309.

23 S. M. Araujo, M. T. de Paula, M. R. Poetini, L. Meichtry, V. C. Bortolotto, M. S. Zarzecki, C. R. Jesse and M. Prigol, Neurotoxicology, 2015, 51, 96-105.

24 T. Sacha, M. Zawada, J. Hartwich, Z. Lach, A. Polus, M. Szostek, E. Zdziłowska, M. Libura, M. Bodzioch, A. Dembińska-Kieć, A. B. Skotnicki, R. Góralczyk, K. Wertz, G. Riss, C. Moele, T. Langmann and G. Schmitz, Biochim. Biophys. Acta, Mol. Basis Dis., 2005, 1740, 206-214.

25 E. Gumpricht, R. Dahl, M. W. Devereaux and R. J. Sokol, Pediatr. Res., 2004, 55, 814-821.

26 A. J. Alija, N. Bresgen, O. Sommerburg, W. Siems and P. M. Eckl, Carcinogenesis, 2004, 25, 827-831.

27 C. Haider, F. Ferk, E. Bojaxhi, G. Martano, H. Stutz, N. Bresgen, S. Knasmüller, A. Alija and P. M. Eckl, Antioxidants, 2017, 6, 1-14.

28 J. T. P. Silva, J. M. T. Geiss, S. M. Oliveira, E. da S. Brum, S. C. Sagae, D. Becker, F. V. Leimann, R. P. Ineu, G. P. Guerra and O. H. Gonçalves, Mater. Sci. Eng., C, 2017, 76, 1005-1011.

29 M. M. Bradford, Anal. Biochem., 1976, 72, 248-254.
30 W. H. Habig, M. J. Pabst and W. B. Jakoby, J. Biol. Chem., 1974, 249, 7130-7139.

31 G. L. Ellman, K. D. Courtney, V. Andres and R. M. Featherstone, Biochem. Pharmacol., 1961, 7, 88-95.

32 M. W. S. Oliveira, J. B. Minotto, M. R. de Oliveira, A. Zanotto-Filho, G. A. Behr, R. F. Rocha, J. C. F. Moreira and F. Klamt, Pharmacol. Rep., 2010, 62, 185-193.

33 R. J. Ruch, S. J. Cheng and J. E. Klaunig, Carcinogenesis, 1989, 10, 1003-1008.

34 R. M. V. Abreu, I. C. F. R. Ferreira, R. C. Calhelha, R. T. Lima, M. H. Vasconcelos, F. Adega, R. Chaves and M. J. R. P. Queiroz, Eur. J. Med. Chem., 2011, 46, 5800-5806.

35 A. H. P. Souza, R. C. G. Corrêa, L. Barros, R. C. Calhelha, C. Santos-Buelga, R. M. Peralta, A. Bracht, M. Matsushita and I. C. F. R. Ferreira, Food Res. Int., 2015, 78, 286-294.

36 D. E. Rubio-Diaz, T. De Nardo, A. Santos, S. de Jesus, D. Francis and L. E. Rodriguez-Saona, Food Chem., 2010, 120, 282-289.

37 J. Yi, T. I. Lam, W. Yokoyama, L. W. Cheng and F. Zhong, Food Hydrocolloids, 2015, 43, 31-40.

38 A. Jain, D. Thakur, G. Ghoshal, O. P. Katare and U. S. Shivhare, Int. J. Biol. Macromol., 2016, 87, 101-113.

39 Y. N. Jiang, H. Y. Mo and D. G. Yu, Int. J. Pharm., 2012, 438, 232-239.

40 A. Charpentier and D. Fournier, Pestic. Biochem. Physiol., 2001, 70, 100-107.

41 M. A. Lebda, M. S. El-Neweshy and Y. S. El-Sayed, Neurotoxicology, 2012, 33, 98-104.

42 D. Dhingra and Y. Bansal, J. Funct. Foods, 2014, 7, 425-434.

43 R. Novo, P. S. Azevedo, M. F. Minicucci, L. A. M. Zornoff and S. A. R. Paiva, Arq. Bras. Cardiol., 2013, 233-239.

44 C. R. McGill, N. R. Green, M. C. Meadows and S. S. Gropper, J. Nutr. Biochem., 2003, 14, 656-662.

45 S. Li, C. Li, S. Jin, J. Liu, X. Xue, A. S. Eltahan, J. Sun, J. Tan, J. Dong and X. J. Liang, Biomaterials, 2017, 144, 119-129.

46 S. R. Blakely, L. Slaughter, J. Adkins and E. V. Knight, J. Nutr., 1988, 118, 152-158.

47 S. A. Heleno, A. R. Rudke, R. C. Calhelha, M. Carocho, L. Barros, O. H. Gonçalves, M. F. Barreiro and I. C. F. R. Ferreira, Food Funct., 2017, 8, 103-110. 